\title{
El Estado en Paraguay durante el gobierno de Carlos Antonio López. Una propuesta teórica-histórica
}

\section{The State in Paraguay during the government of Carlos Antonio López. A theoretical-historical approach}

\author{
Magdalena López \\ Instituto de Investigaciones Gino Germani, \\ Universidad de Buenos Aires \\ Grupo de Estudios Sociales sobre Paraguay del \\ Instituto de Estudios de América Latina y el Caribe (Argentina) \\ magui@sociales.uba.ar
}

\begin{abstract}
Resumen
El período del primer López significó un gran despliegue de potencialidades estatales que cubrieron al mismo tiempo la creación de una constitución, la estructuración de una forma de gobierno, el desarrollo de una matriz productiva relativamente original, el intento de formar parte de la región como una unidad soberana autónoma, la patrimonialización mediante adquisición de edificios para la administración nacional, etc.

La historiografía paraguaya ha avanzado mucho en la producción de obras rigurosas respecto a las características políticas, sociales, económicas y regionales del Gobierno de Carlos Antonio López. Sin embargo, los debates en torno al surgimiento del Estado nacional en Paraguay han quedado relegados de estos estudios, pues han sido desarrollados desde otras disciplinas.

Este artículo no propone una valoración de esta forma de organización, sino una descripción de su estadio y consolidación. Analizamos el caso paraguayo a partir del modelo teóricometodológico de Oscar Oszlak, utilizando cuatro requisitos de estatidad que nos permitirán sostener que, mientras el gobierno de Gaspar Rodríguez de Francia no constituyó un Estado nacional, el de Carlos Antonio López si se acercó a esta figura conceptual.
\end{abstract}

\section{Palabras Clave}

Paraguay; Teorías del Estado Nacional; Surgimiento del Estado Nacional en América Latina; Debates históricos conceptuales; Siglo XIX.

\footnotetext{
Abstract

The era of the first Lopez meant a great display of state potentialities that covered at the same time the creation of a constitution, the structuring of a form of government, the development of a relatively original productive matrix, the attempt to be part of the region as an autonomous sovereign unit, the acquisition of buildings for the national administration, among others.
} 
Paraguayan historiography has advanced a lot in the production of rigorous literature regarding the political, social, economic and regional characteristics of the Government of Carlos Antonio López. However, the debates around the emergence of the national State in Paraguay have been relegated from these studies, since they have been developed from other disciplines.

This article does not propose an assessment of this form of organization, but rather a description of its stage and consolidation. We analyze the Paraguayan case based on the theoretical-methodological model of Oscar Oszlak, using four requirements of stateness that will allow us to maintain that while the government of Gaspar Rodríguez de Francia did not constitute a national State, the one of Carlos Antonio López approached better this conceptual figure.

\section{Keywords}

Paraguay; Theories of the National State; Emergence of the National State in Latin America; Historical and conceptual debates; 19 th century.

\section{Introducción 1}

En el tiempo de la colonia, el Estado se caracterizaba por un conjunto de instituciones, procedimientos, normativas y autoridades derivados de las metrópolis, por la condición colonial del dominio y la organización del poder.

Luego de la independencia en la región, los Estados nacionales ${ }^{2}$ adquirieron rasgos diferenciales con una nueva territorialidad, que los obligó a dirimir límites (materiales y simbólicos) hacia afuera o adentro de los nuevos ejidos de poder. Se desarrollaron en paralelo procesos de ciudadanización y de territorialización, al tiempo que se innovaron nuevas formas de organización política, derivadas de los clivajes y enfrentamientos históricamente presentes en esos espacios.

La historiografía ha identificado un "Estado Liberal" en Paraguay, como institución con estatidad "cuantificable" - es decir, portadora de un conjunto de requisitos atribuibles al Estado- recién a partir de 1870, luego de que el Ejército Aliado se impusiera sobre el territorio, ocupase y gobernase, sancionando la que se conoció como "primera Constitución liberal". Sin embargo, consideramos que el período existente previo a la Guerra contra la Triple Alianza también debe ser analizado con intención de identificar qué tipo de Estado existía.

Paraguay declaró su independencia en 1811 y, al tiempo de renunciar al dominio español, también se opuso a obedecer los mandatos de Buenos Aires. En 1813, obtuvo el estatus de República y, de la mano de Gaspar Rodríguez de Francia en 1814, se inició la Dictadura Suprema, que se convertiría en Perpetua en 1816.

El Doctor Francia gobernó el Paraguay hasta 1840, año de su muerte. Algunos estudios han posicionado al gobierno de Francia como uno de los más beneficiosos

\footnotetext{
1 Agradezco los comentarios de los dos evaluadores que ayudaron a mejorar este artículo.

2 En este texto, a partir de esta sección, referiremos a Estado y Estado nacional como sinónimos, para evitar la reiteración constante.
} 


\section{El Estado en Paraguay durante el gobierno de Carlos Antonio López. Una propuesta teórica-histórica}

para el Paraguay, llegando incluso a conceptualizarlo como socialismo de Estado, dictadura democrática, entre otros ${ }^{3}$.

Para los fines de este artículo, entendemos que su gobierno fue una dictadura con un monopolio del poder, que no existió división de poderes y que la mayor preocupación estaba puesta en evitar una invasión de las potencias vecinas que estaban, al igual que Paraguay, ejerciendo un poder conflictivo sobre sus territorios y disputando límites geográficos y administrativos. Sobresalió especialmente la centralidad del poder, la carencia de un sistema normativo y legal que inaugurase un nuevo orden estatal y la reproducción de una sustancial cantidad de prácticas y ejercicios coloniales de la autoridad. A pesar de esto, consideramos que la experiencia francista fue un intento diferencial de Estado, porque su intención marcada por conservar la autonomía y la independencia, señalan un proceso de ruptura del orden previo, a pesar de las múltiples continuidades.

En lo económico, el Estado era el intermediario de las transacciones comerciales y un meticuloso recaudador de impuestos. Además, su dictadura estuvo caracterizada por el aislamiento internacional y la baja exportación de productos nacionales. Organizó un sistema de producción de tierras sostenido en el arrendamiento a precios económicos a campesinos con la condición de que las utilizasen para producir comida o como terrenos de pastoreo.

Con el fin de instaurar un orden social determinado, desarticuló el poder de las familias más poderosas (preferentemente las de origen español) con algunas estrategias como la desarticulación de algunos espacios de socialización de la elite, la expropiación de algunos bienes, la ruptura de algunos privilegios económicos.

En el plano religioso, el poder económico de la Iglesia fue progresivamente diluido. Su rol prominente en la educación fue reemplazado por mayor presencia estatal en la temática.

Uno de sus objetivos centrales fue el de sostener la independencia frente a potencias vecinas, que se constituían en un potencial peligro inminente (algo que se extendió a los gobiernos posteriores). Con este fin, perpetuó algunas instituciones del orden colonial borbónico que coexistieron con los cambios que la independencia trajo

\footnotetext{
${ }^{3}$ Un ejemplo de esto es la obra de Richard Alan White y los trabajos de Mário Maestri, centralmente su obra "Paraguay: la república campesina, 1810-1865" publicada en Asunción (Intercontinental Editora) en 2016. En esta obra, Maestri desarrolla la hipótesis de que el Paraguay de 1811 a 1840, la era francista, fue el escenario de un proceso único en la región que combinó una revolución democrático popular y consolidó al Estado moderno, sostenido sobre el pequeño campesinado encolumnado detrás de la figura centralizada de José Gaspar Rodríguez de Francia. El autor sostiene también que la era posterior, la lopista, rompió la alianza del Estado con los campesinos y forjó lazos con los hacendados y chacreros, con el fin de consagrar un modelo de desarrollo centralmente agroexportador. En contraposición a estas teorías, Mario Pastore, texto "State-led "industrialization"; the evidence on Paraguay, 1852-1870", publicado por Center for Latin American Studies, Tulane University, New Orleans, LA, Latin American Studies Program, Cornell University en 1993, critica el gobierno de Carlos Antonio López porque se sostuvo sobre formas institucionales atrasadas y baja modernización. Respecto a todo el período de independencia, sostiene "El 'original', 'sui generis' experimento del período nacional temprano en el Paraguay no fue sino la prolongación del militarismo, absolutismo, y mercantilismo coloniales al período nacional temprano, que acentuó algunas facetas del mercantilismo colonial y le dio una apariencia particular" (p. 32).
} 


\section{Magdalena López}

aparejados. El aparato administrativo estuvo centrado en la Secretaria de Estado, el Ministro de Finanza y Tesoro y, hasta 1824, en los Cabildos coloniales.

En lo que respecta a la justicia, las leyes que organizaron el período fueron las coloniales. Esto cambió recién en la presidencia de Carlos Antonio López (CAL) que se extendió entre 1844 y 1862.

Tras la muerte del Doctor Francia, se sucedieron diferentes formas de organización política que incluyeron presidentes provisionales, el Triunvirato y, tras la reunión del Congreso, el Consulado. Este último se conformó por Mariano Roque Alonso y Carlos Antonio López en marzo de 1841 y, para su clausura en marzo de 1844, López ya había logrado desplazar a su par del centro de la escena decisoria. En este trabajo, consideraremos el período del Consulado como parte del Gobierno de Carlos Antonio López, por la preeminencia y relevancia que su figura tuvo en este órgano gubernativo.

Las trayectorias de los diferentes Estados surgidos en torno a la independencia se asociaron a los patrones de desarrollo histórico. Oszlak (2014) explica que, para los procesos de formación estatal, tuvieron determinantes sociales y que, para saber las condiciones de existencia de los primeros, necesitamos reconocer el grado de desarrollo de los segundos (existencia de una idea o sentimiento de nación; difusión, acatamiento y extensión de relaciones de producción, sistemas de intercambio económico, concepciones ideológicas predominantes, cristalización de las clases sociales, entre otros). Además, a medida que el Estado se asocia a estos estadios de desarrollo social, modifica los mismos, generando un círculo de retroalimentación. En este sentido, Bohoslavsky y Godoy Orellana (Bohoslavsky y Godoy Orellana' 2010:15-34) sostienen que las decisiones políticas son también el resultado de disputas de diversas autoridades, de la Iglesia, de burócratas y agencias estatales, partidos, corporaciones, líderes y población. Al mismo tiempo que la política busca establecer un orden sobre estos agentes, los agentes modifican la política que buscaba organizarlos. Las decisiones "no tienen siempre un contenido ideológico previo" (Bohoslavsky y Godoy Orellana', 2010: 22) y muchas veces se constituyen en un ensayo y prueba que fracasa o muta en su proceso.

Al estudiar el surgimiento del Estado nacional en América Latina, y en nuestro caso específico, en Paraguay, nos vemos ante un conjunto de desafíos generales y particulares. Uno de estos es que la teoría del Estado ha surgido en torno a los Estados europeos, por lo que la reflexión epistemológica debe estar focalizada en evitar la extrapolación acrítica y descuidada de conceptos, o el exceso de mediaciones para lograr que dicho encuadre teórico aplique a la realidad latinoamericana.

En otras de sus producciones, Oszlak (2011: 115-141) nos presenta el problema de rastrear la evolución de un proceso, utilizando las categorías analíticas que son el producto histórico acabado de ese proceso (nación, capitalismo, burocracia, entre otros). Esto nos conecta con otro desafío, que es la tentación de usar categorías europeas para terminar arribando a la falsa conclusión de que ningún Estado 


\section{El Estado en Paraguay durante el gobierno de Carlos Antonio López. Una propuesta teórica-histórica}

Latinoamericano responde a ese modelo, a priori superior y teleológicamente devenido.

A esto, le sumamos la dificultad conceptual de definir a 'Estado' dando cuenta de las generalizaciones sin dejar de lado la especificidad. Es decir, lograr una conceptualización tan precisa que permita explicar aquello que tienen en común el surgimiento del Estado en, por ejemplo, Chile, Bolivia, Uruguay, Argentina y Paraguay; sin dejar de remarcar las trayectorias políticas, sociales y económicas que hicieron que cada Estado adquiera particularidades diferenciadas del resto.

Particularmente para el caso paraguayo, una de las problemáticas analíticas que encontramos, es que la historiografía existente ha encontrado en Paraguay un Estado Liberal, como institución con estatidad "cuantificable" —es decir, portadora de un conjunto de requisitos atribuibles al Estado-a partir de 1870, luego de que el Ejército Aliado se impusiera sobre el territorio, ocupase y gobernase, sancionando la considerada primera Constitución liberal. ${ }^{4}$

Lempérière (2007) sostiene que los historiadores han quedado excluidos de los avances del conocimiento teórico en torno al Estado en el contexto hispanoamericano. Para ella, esos aportes los han elaborado sociólogos y politólogos, sobre lo que, agregamos, se profundizó el problema de la escisión entre los casos históricos y los modelos teóricos. Aportando al debate en ambos campos, en este artículo abordaremos el período con una perspectiva específica: la hibridación de la ciencia política y la historia. Trataremos de delinear las bases del Estado de Carlos Antonio López, a partir de una propuesta teórica y conceptual. Sin embargo, reconocemos que podrán surgir críticas desde ambas disciplinas por la complejidad que implica aplicar un modelo teórico de análisis a un caso específico, intentando delimitar generalidades y particularidades.

En este texto, pretendemos resaltar algunos aspectos del Estado durante el gobierno de Carlos Antonio López, discutiendo al mismo tiempo con las expresiones nacionalistas de la historiografía de la primera mitad del Siglo XX y con aquellas tensiones más contemporáneas que plantean a Paraguay como el país de la excepcionalidad teórica. En el primer apartado, abordaremos algunos elementos centrales de la teoría del Estado, a partir de una selección muy acotada de autores. En el segundo, mapearemos algunos estudios existentes sobre el período y la idea de Estado que -más o menos explícitamente- estos trabajos exponen. En el tercero, revisaremos algunos datos históricos del período de Carlos Antonio López, a la luz del encuadre metodológico-teórico propuesto por Oscar Oszlak. Finalmente, derivaremos un conjunto de reflexiones que intentarán condensar conclusiones y disparar nuevas preguntas.

\footnotetext{
${ }^{4}$ Entre los autores que consideran el período iniciado en 1870 como el inaugural de la política liberal en Paraguay -sobre todo por el rasgo liberal de la Constitución sancionada en este año- podemos nombrar a: (Kleinpenning, 2009; Couchonnal Cancio, 2017; Abente Brun, 1989; Rivarola, 2010; Otero, 1978; Caballero Campos, 2013; Fuentes Armadans, 2018).
} 


\section{Magdalena López}

\section{Estado nacional. Un breve repaso}

Rosanvallon (1990) retoma una de las paradojas de los estudios del Estado en la historia y las ciencias sociales: existe en la historiografía una práctica habitual de referir al Estado como institución, actor y eje central de procesos de diversa índole, pero esto no se acompaña con un desarrollo teórico específicamente dedicado a los problemas del Estado como centro del análisis, en su caso, aplicado al caso Francés del Siglo XIX.

Con cinco años de diferencia, Skocpol plantearía que, a pesar del retorno del Estado como eje analítico y la proliferación de estudios interesados en él como actor e institución central, "estos estudios diversos no han estado vinculados por ningún programa de investigación o teoría general explícitamente compartida". (Skocpol,1995:3)

Para la autora, la forma de revertir este problema no es armar una gran teoría restaurada o novedosa del Estado, sino analizar fundamentada y sólidamente las regularidades causales y particularidades en las historias de los Estados, las estructuras sociales y las relaciones transnacionales.

Además, complementa Lempérière, entre los estudios disponibles del Estado, existe una fragmentación conceptual y metodológica que ha generado, por ejemplo, que no se logre consensuar una definición de Estado que sea una base de investigación. Uno de los trabajos que, la autora expresa, logran romper con estos límites es el de Oscar Oszlak, pues abordó los problemas concretos de la creación de un Estado en Hispanoamérica, combinado con una propuesta teórica que pretende darle un matiz analítico más amplio. Es decir, la precisión de un caso específico con sus tiempos, periodización y problemáticas y la pretensión de universalidad de un modelo de abordaje. ${ }^{5}$

Kelsen incorporó el elemento de la temporalidad como un factor importante al momento de analizar la fundación de los Estados. En su análisis cada organización estatal estaba atada a un ritmo de tiempo que marcaría su nacimiento e incluso su extinción.

La fórmula de Kelsen, recupera Lempérière (2007: 48) "nos recuerda simplemente que el Estado y las instituciones tienen su propia temporalidad, así como también su sistema de referencias y su racionalidad propia, de tal suerte que estudiarlo impone escoger conceptos, referencias y categorías de análisis análogas al objeto".

Hacemos nuestra la definición de Estado de Guillermo O’Donnell (1978: 1158) "componente específicamente político de la dominación en una sociedad territorial delimitada. Por dominación (o poder) entiendo la capacidad, actual y potencial, de imponer regularmente la voluntad sobre otros, incluso pero no necesariamente contra

\footnotetext{
${ }^{5}$ Existen otros trabajos que teorizan la cuestión del Estado también a partir de un caso específico. Un ejemplo de esto es la apuesta teórica de O’Donnell, G. (1978). "Apuntes para una teoría del Estado". Revista Mexicana de Sociología, Vol. 40, № 4, pp. 1157-1199. En este trabajo, O’Donnell propone analizar las características de todo Estado Capitalista para poder definir con claridad el caso del Estado Burocrático-Autoritario en Argentina y en otros países de Latinoamérica.
} 


\section{El Estado en Paraguay durante el gobierno de Carlos Antonio López. Una propuesta teórica-histórica}

su resistencia. Lo político en sentido propio o específico lo entiendo, entonces, como una parte analítica del fenómeno más general de la dominación: aquella que se halla respaldada por la marcada supremacía en el control de los medios de coerción física en un territorio excluyente delimitado". Para el autor, los recursos sobre los cuales se solventa la dominación como una dinámica relacional son: 1) control de medios de coerción física. 2) Control de recursos económicos. 3) control de recursos de información, incluyendo conocimientos científicos-tecnológicos. 4) control ideológico que hace que el dominado asuma como natural y justa la asimetría con el dominante.

En su obra de 1968, Nettl (1968: 559-592) se preguntó sobre las funciones que desarrolla el estado y sobre quien las ejecuta cuando éste está ausente. Uno de los elementos centrales que desarrolla el autor es la existencia de requisitos de estatidad, concepto que reutilizará Oszlak. La estatidad es un conjunto de propiedades que definen la existencia de un Estado. Incluye capacidades materiales para controlar y extraer o redistribuir recursos, como simbólicas para evocar, crear e imponer identidades y lealtades colectivas entre ciudadanos.

Quizás uno de los problemas centrales de la propuesta teórica de Nettl es que está prioritariamente pensada para Estados europeos y, en todo caso, por extensión, al estadounidense. Esto se debe, entre otras razones, en que la disciplina de Teoría del Estado surgió en Europa, para analizar a Europa, siendo luego extendida al resto de los territorios de influencia europea.

Dos intentos más holísticos de estudiar el inicio, la consolidación y el devenir del Estado en América Latina lo constituyen los textos de Centeno (2002) y de LópezAlves (2003), ambos provenientes de la academia estadounidense y con la propuesta de analizar numerosos casos de Estados en perspectiva comparada.

Nos detendremos brevemente en dos de sus trabajos, antes de presentar la teoría de Oszlak, que utilizaremos en este trabajo.

En su libro "Blood and Debt. War and the Nation-State in Latin America", publicado en 2002, Centeno compara los casos de surgimiento del Estado en Latinoamérica con Europa, para afirmar que la fuerza del Estado en América Latina no puede medirse en base a su performance como proyector del territorio, pues en esto mostró, a diferencia de los europeos, un potencial limitado. Para el autor, el Estado no dominó las sociedades, y aunque presentó rasgos altamente despóticos fue débil en infraestructura. Lo despótico derivaba de la incapacidad de las elites de consensuar políticas con la sociedad civil y la debilidad de la incapacidad institucional del Estado para implementar decisiones.

Al igual que López-Alves, insta a analizar la relación entre el conflicto político y el desarrollo de la formación estatal. Su interés es encontrar la conexión probabilística entre guerra y desarrollo del Estado.

Para el autor, los estados latinoamericanos se caracterizan por el debilitamiento del poder y no por la concentración del mismo. Como hipótesis general, sostiene que lo países latinoamericanos desarrollaron un nivel de militarización comparativamente menor. Sin embargo, esto no se cumpliría para el caso paraguayo, pues para Centeno, 


\section{Magdalena López}

este Estado bajo dominio de López es una excepción. Para el autor, tanto Chile como Paraguay se caracterizan por un alto nivel de belicosidad, que le confirmarían la idea de Estados de gran capacidad y su probabilidad a participar en guerras. Además, les atribuye a estos dos países la polémica afirmación de que ambos podían fácilmente definir la nación a la que representaban, algo que los demás nuevos estados independientes no podían hacer.

El autor sostiene que ningún Estado latinoamericano sufrió violentamente por guerras y que no existieron conflictos internacionales, aunque excluye de esta regla a Paraguay, Colombia y México.

Centeno concluye que lo característico del caso chileno y paraguayo es también la centralidad del Estado en el proceso de modernización, algo que Pastore (1993) rechaza, por considerar que la hipótesis de modernización liderada estatalmente es errada y no sólo no se logró en términos económicos, sino que estuvo relegada también en términos institucionales y de régimen político.

Respecto a la hipótesis de Centeno de la relevancia del ejército como eje de estabilidad del nuevo Estado, creemos con Maestri que la característica de este ejército era su conformación campesina, mucho más que su formación bélicamilitar. Es decir, para entender el concepto de la época de ejército, resultaría más interesante analizar la producción agraria estatal de estos sujetos, y como describe Milda Rivarola, su incorporación como fuerza de trabajo, que su conscripción y rol militar, como fuerza de choque bélico.

Desde un análisis semejante al de Centeno, en cuanto a amplitud y metodología, Fernando López-Alves, en "La formación del Estado y la democracia en América Latina 1830-1910" analiza las relaciones civiles-militares durante el Siglo XIX en toda la región latinoamericana. Su interés radica en analizar si la construcción institucional del Estado influye a largo plazo en la forma de hacer política dentro de este territorio.

Para el autor es mucho más importante el ejercicio de la política que las diferencias más tradicionales de nivel de desarrollo, calidad y formación de las fuerzas de trabajo y productivas y la disponibilidad de recursos naturales. Para esto, indica revisar a) el rol de las FFAA en la formación del Estado, su conformación y la proveniencia de sus miembros (revisar, por ejemplo, la presencia de sectores urbanos y rurales en las guerras de independencia); b) Las características de las coaliciones políticas que sustentan los regímenes políticos que dan diversidad a los arreglos institucionales; c) el desarrollo económico (cuanto más desarrollo, regímenes más inclusivos); y d) las formas en las que el clivaje en torno al sector rural es incorporado a las prácticas políticas y militares, que cambian los resultados institucionales.

Si bien Paraguay (junto a Venezuela) no constituye un caso central de la obra de López-Alves, sí es incorporado como formato alternativo de conformación del Estado y estructuración de regímenes políticos.

López-Alves afirma que en el proceso de centralización de poder y el devenir el Estado paraguayo, el aparato militar fue central para incorporar a las masas pobres 


\section{El Estado en Paraguay durante el gobierno de Carlos Antonio López. Una propuesta teórica-histórica}

(especialmente rurales) a la guerra (y, a partir de allí, construirlos como un sujeto político) y eso marcó una tendencia hacia la conformación de regímenes autoritarios.

Respecto a la producción de López-Alves, Ignacio González Bozzolasco (2017) elaboró un conjunto de críticas, sostenidas en bibliografía no considerada por el trabajo original. Además, González remarcó el sesgo de producción anglosajona que caracteriza a este trabajo, dejando por fuera análisis en otros idiomas o provenientes de otros circuitos editoriales y académicos latinoamericanos y paraguayos.

Hacemos nuestras algunas de estas críticas, reflexionando junto con él que el uso de Paraguay como caso testigo no representa necesariamente el repertorio histórico del país.

González Bozzolasco discute con López-Alves sobre

"en primer lugar, el rol determinante atribuido al ejército para la incorporación de los pobres rurales; en segundo lugar, la afirmación de que en el Paraguay se desarrolló un sistema de esclavitud controlada desde el Estado; y, en tercer lugar, la consideración de una influencia determinante del ejército luego de la Guerra de la Triple Alianza”. (González Bozzolasco, 2017:78)

Para González Bozzolasco la base de apoyo del naciente Estado libre paraguayo no fue el ejército, como sostiene López-Alves, sino los pequeños y medianos productores rurales y el campesinado pobre. En esta, se apoya en las investigaciones de Guerra Vilaboy (1984), White (1989), Pastore (1993), Campos (2010), entre otros.

En este sentido, la incorporación de las masas pobres rurales a la política se realizó, afirma González, a partir de las medidas tomadas por Francia, tendientes a la reforma agraria. Esta fue la base de consolidación del ejército que según indica Bozzolasco, siguiendo a White, no fue especialmente numeroso.

La idea de López-Alves de un Estado fuerte luego de la Guerra contra la Triple Alianza, sostenido por el rol preponderante del aparato militar, es fuertemente rebatida por numerosos estudios que plantean que Paraguay debió construir hegemonía a partir de un Estado debilitado (Galeano, 2009), que Paraguay permaneció por décadas devastado por las consecuencias de la postguerra (Capdevila, 2010), que las consecuencias de la guerra afectaron tanto al Estado como a la política, a las elites y al modelo de desarrollo (Brezzo, 2011). Además, autores con producciones muy importantes, han señalado que los partidos políticos tuvieron incluso en las postrimerías de la guerra un factor central en la reorganización política-estatal y reestructuración del ejercicio del poder (Chartrain, 2013).

Habiendo repasado estos aportes y reconociendo la existencia de otros estudios, queremos incorporar elementos de la teoría de Oszlak. Que tiene el beneficio de intentar pensar el Estado en América Latina con sus especificidades, pero también con aquello que "arrastró" de la situación colonial. 
"En un sentido ideal-abstracto concibo al Estado como una relación
social, como la instancia política que articula un sistema de
dominación social. Su manifestación material es un conjunto
interdependiente de instituciones que conforman el aparato en el que
se condensa el poder y los recursos de la dominación política. Este
doble carácter del Estado encuentra un cierto paralelismo en el
concepto de nación. En efecto, pese a las ambigüedades y
discrepancias que aún rodean su definición, puede argumentarse que
en la idea de nación también se conjugan elementos materiales e
ideales. Los primeros se vinculan con el desarrollo de intereses
resultantes de la diferenciación e integración de la actividad
económica dentro de un espacio territorialmente delimitado"
(Oszlak, 2011: 117)

Rescatamos del autor la conceptualización del surgimiento del Estado nacional como la conformación de la instancia política de dominación en una sociedad y la materialización de un conjunto de instituciones que actúan de manera articulada y permiten el ejercicio de la dominación.

"La existencia del Estado presupone entonces la presencia de condiciones materiales que posibiliten la expansión e integración del espacio económico (mercado) y la movilización de agentes sociales en el sentido de instituir relaciones de producción e intercambio crecientemente complejas mediante el control y empleo de recursos de dominación. Esto significa que la formación de una economía capitalista y de un Estado nacional son aspectos de un proceso único -aunque cronológica y espacialmente desigual. (...) Pero además implica que esa economía en formación va definiendo un ámbito territorial, diferenciando estructuras productivas y homogeneizando intereses de clase que, en tanto fundamento material de la nación, contribuyen a otorgar al Estado un carácter nacional" (Oszlak, 2011: 117).

Como describimos anteriormente, Oscar Oszlak (2011) explica que la existencia (o, agregamos, su grado de desarrollo) de un Estado nacional puede evidenciarse mediante la medición de un conjunto de requisitos de estatidad (propiedades o "condiciones de ser" Estado). Resume su propuesta teórica en cuatro propiedades: 1) Capacidad de externalizar el poder, logrando incorporarse a un sistema de relaciones interestatales que reconozca al nuevo Estado como una unidad soberana; 2) Capacidad de institucionalizar la autoridad mediante una estructura de relaciones de poder que le garantice el monopolio sobre los medios de coacción; 3) Capacidad de diferenciar su control, creando un entramado funcionalmente diferenciado de instituciones públicas que tengan legitimidad para a) extraer recursos de la sociedad civil, b) realizar su tarea mediante funcionarios profesionalizados, y c) centralicen el control de las diferentes actividades que llevan 


\section{El Estado en Paraguay durante el gobierno de Carlos Antonio López. Una propuesta teórica-histórica}

adelante; y por último, 4) Capacidad de internalizar una identidad colectiva mediante la emisión de símbolos que profundicen el sentimiento de pertenencia y habiliten un mayor control ideológico. Evaluaremos estos cuatro elementos para el período de gobierno de Carlos Antonio López más adelante.

\section{"Se dice de mi": retomando algunos escritos sobre el Estado en Paraguay durante el gobierno de Carlos Antonio López}

La historiografía sobre el lopismo en Paraguay puede analizarse, al igual que la disciplina en otros Estados, según tiempos de producción con características muy diferentes tanto en la forma de interpretar el pasado, como en la intención de utilizar esa visión para dialogar con el presente.

En diversos trabajos, Liliana Brezzo (2008) abordó las disputas sociopolíticas existentes en el contexto contemporáneo de los historiadores y cómo esto modificó su percepción del pasado. Como describe la autora, el clivaje central en esta dicotomía historiográfica lo constituyó la figura de Francisco Solano López ${ }^{6}$ y su participación en la Guerra Grande.

Hasta alrededor de la década del 1910, la producción intelectual en torno a la construcción del pasado se asociaba a la crítica estricta a la figura del Mariscal, así como a la reiteración en los rasgos autoritarios y dictatoriales de los gobiernos previos. Resume Brezzo (2008: 17) “el resultado feliz del enfrentamiento había sido la liberación del pueblo paraguayo del sistema bárbaro impuesto por los gobiernos tiránicos que lo habían mantenido aislado de las naciones civilizadas".

Como respuesta a este lineamiento, surge una lectura alternativa que buscaba recrear el pasado nacional, exaltando la figura del Mariscal, recuperando el rol de resistencia y heroísmo del pueblo paraguayo durante la Guerra y reivindicando los gobiernos previos, por su unicidad y originalidad dentro de la región. Ignacio Pane, Juan O’Leary y Manuel Domínguez fueron centrales en esta perspectiva.

Nos interesa indagar sobre un conjunto de obras fuertemente marcadas por este nuevo abordaje, el horror de la Guerra Grande y la necesidad de rescatar un relato histórico de grandeza, proyectos políticos y económicos modernizantes y punta de flecha del desarrollo regional. En esta línea encontramos trabajos continuadores de los intelectuales mencionados (Pérez Acosta,1948; Chávez, 1955; Pastor Benítez,1990; González, 1935), como los de Juan Pérez Acosta, Julio César Chávez, Justo Pastor Benítez y Natalicio González.

Esta literatura tiene un discurso nacionalista y triunfalista que naturaliza la forma de ejercicio del poder de López y lo transforma en héroe. Estos trabajos, abordan de manera exhaustiva un conjunto de medidas tomadas y construyen, a partir de esta caracterización, una idea de Estado que no está abiertamente especificada. Es decir,

\footnotetext{
${ }^{6}$ Para conocer más sobre la discusión en torno a la figura de López y una propuesta de periodización en torno a su rol histórico, recomendamos Herib Caballero Campos. "Entre el recuerdo y la reivindicación: apoteosis, el álbum conmemorativo de la inauguración del Panteón Nacional de los Héroes". Revista Folia Histórica del Nordeste, № 24, 2015, pp. 115-130.
} 
si bien no sostienen qué es lo que considerarán Estado, ni determinan cuáles características debe tener un sistema de organización social para considerarse un Estado (en cualquiera de sus formas), enumeran un conjunto de atributos, bajo el eje de contención del "Estado". Llenan de contenido un concepto que no definen ni complejizan, lo que dificulta la teorización sobre el período. Además, se caracterizan por una intensa y florida adjetivación de los textos, plagada de calificaciones positivas.

"Es un hijo legítimo de la tierra. Escucha en guaraní, pero se expresa en español. Sus medidas en el futuro tendrán el color nacional, porque su diccionario es el país. Sus costumbres son patriarcales y hasta en sus defectos se revela su carácter de viejo señor español y campesino guaranizado. Es asunceño de nacimiento y formación intelectual, pero campesino de espíritu y por lo tanto tiene más amplios horizontes (...) Es un paraguay rapó piré (un paraguayo auténtico), un americano de verdad. Observa, estudia y busca soluciones dictadas por la realidad. El buen sentido es la fuente de su sabiduría; sencillo y lógico, hasta sus arbitrariedades respondieron siempre al propósito de someter a los hombres y las cosas a un interés superior, en beneficio de la colectividad. En ese sentido, es un político realista, pero no en el sentido de la falta de escrúpulos, pues, la ética cristiana inspira sus actos" (Pastor Benítez, 1990:19).

En la misma línea, retomando los escritos de Carlos Antonio López en La Emancipación Paraguaya, Juan Natalicio González realiza una presentación de la obra de López en la que expresa:
"escritor nato, prosador elegante, dueño de un estilo vario, múltiple, movido y poderoso como el mar, Carlos Antonio López se destaca por una característica común a los mayores publicistas del Paraguay: no le impulsa a escribir ningún afán de nombradía o de gloria, sino el gozo de servir a su pueblo, del que se erige en vocero y defensor (...) Carlos Antonio López trabajó, infatigablemente, con sabiduría y fértil genio realizador, a consolidar esa libertar y crear ese poderío. Cuando lo sorprendió la muerte, el Paraguay era un vasto taller, donde florecían las artes y las industrias, se movilizaban todas las riquezas potenciales a beneficio exclusivo del pueblo y donde la cultura se expandía en forma realmente explosiva". (González, 1942: 27).

En cuanto al concepto de Estado, llegado el caso, estos autores describían el gobierno de López, pero no el encuadre estatal en el que el mismo se desarrollaba. Quizás, la cercanía del modelo de Estado y de política de gobierno de este período, colaboró con que los autores que lo analizaron posteriormente, no se vieran compelidos a desarrollar teóricamente el concepto. 


\section{El Estado en Paraguay durante el gobierno de Carlos Antonio López. Una propuesta teórica-histórica}

Para delinear un ejemplo, podemos repasar la obra de Pérez Acosta (Pérez Acosta,1948) y analizar que si bien no describe el Estado, dedica la primera sección de su libro a describir los aportes en defensa nacional, industria nacional y desarrollo económico del período (por ejemplo, desarrollando las adquisiciones diversas, el arsenal y astillero, la fundición de Ybycui, el ferrocarril, el telégrafo, la reorganización de la Marina de Guerra y la Mercante, los planes de formación educativa en el exterior); la segunda remite a ciertos episodios políticos de Carlos Antonio López, y la tercera apunta a los cambios acaecidos en el arte, la cultura, la educación y la religión. Existe en este panorama, que se pretende neutral, una idea de Estado que, si bien no está polemizada, subyace invisible. Elegir mostrar estos "logros" y no otros marca que hay una idea de Estado en tanto desarrollo y organización de variables económicas, administrativas, educativas y artísticas.

En estos trabajos existen varios ejes argumentativos en común, uno de estos es el de justificar la centralidad del poder en un factor local, autóctono del Paraguay, en su formación socio-económica y geográfica, localista.

Este "destino esperado" que asocia particularidades territoriales y sociohistóricas con el desarrollo del Estado y del sistema de gobierno, también está presente en $E l$ Paraguay eterno y en El Milagro Americano de Natalicio González (González, 1935, 1983). A la constitución brava y superior de los indígenas guaraníes, se le sumó la mezcla española ${ }^{7}$ y la particularidad de ocupación de los jesuitas. Esto dio como resultado una sociedad que, en cierta forma, parece exigir un Estado férreo que reclama liderazgos centralistas y unipersonales. Al respecto, acordamos con Telesca (2010:151) en que "su intención será demostrar que la propia naturaleza del paraguayo, desde su misma raza, rechaza el sistema liberal y convoca un sistema con un poder ejecutivo fuerte".

Natalicio González, entonces, plantea la existencia de una nación brava desarrollada por la mestización de algunos rasgos esenciales de diferentes razas, que generaron la necesidad de gobiernos con perfil centralizado, autoritario y omnipresente.

Desde una perspectiva diferente, rescatamos el trabajo de Creydt (1963), Formación Histórica de la Nación Paraguaya por su originalidad y su apuesta analítica. En este trabajo, el autor desacredita los trabajos anteriormente mencionados por considerarlos reaccionarios, colonialistas o acríticos (Castells, 2011).

$\mathrm{Al}$ igual que los historiadores a los que critica, el autor plantea que su historia es la que realmente sucedió, y no la reversionada por los falsificadores (lo mismo que los anteriores hicieron con la historia antilopista previa).

En la obra de Creydt, el etapismo y la revolución como meta casi teleológica son dos estructuras centrales. Para el autor, la nación paraguaya se puede periodizar en cuatro tiempos y la del período que abordamos se corresponde con "la época de la primera revolución nacional (1811-1870)”. Allí, Creydt marca como sujeto dinámico

\footnotetext{
${ }^{7}$ En expresión de González: "los conquistadores clavaron su hogar en el nuevo país dominado, y no tardaron en mezclar su sangre con la del indígena. De este cruce surgió un nuevo elemento étnico: el mestizo, inteligente y fuerte, de bella gallarda apostura". González, N. (1926). Solano López y otros ensayos. Paris: Editorial de las Indias.
} 


\section{Magdalena López}

de cambio social al campesinado y como agente del control y de la imposición de diferentes sectores de la elite a Rodríguez de Francia y a López.

Por su carácter progresivo en cuanto a acumular avances para el desarrollo del capitalismo, desarrollar las fuerzas productivas y proletarizar a la población campesina, Creydt considera que el gobierno de López también fue positivo. Lo que guía su lectura es que, una vez alcanzado un estadio de desarrollo bajo la cabeza de una burguesía nacional, el campesinado y el proletariado lograrían hacerse del poder político.

Si bien las causas de aceptación del período del viejo López varía entre estos autores, y su finalidad es diferente, resulta interesante ver como para todos, el camino que transitó el Paraguay durante este período fue el del progreso, el desarrollo, el aumento de ciertas tensiones y contradicciones que el liderazgo de López supo encauzar, la estabilización, la inserción en un sistema internacional de comercio y diplomático, todo con una finalidad superior al mero transcurrir político: la modernidad, la revolución, el liderazgo regional, etc.

Posteriormente, surgió una numerosa bibliografía que, con mucha rigurosidad y brindando un aporte indiscutido (Susnik ,1992; Potthast, 1996; Pastore, 1972; Rivarola, 2010; Heyn Schupp, 1982; Cooney y Whigham, 1994; Telesca, 2009; Telesca, 2017; Caballero Campos; 2009; Chartrain, 2013; Viola, 2004; Areces y González de Bosio, 2017; Areces, 2010), comenzaron a discutir algunas de las grandes hipótesis del período. Si bien ninguno analiza teóricamente la cuestión del Estado, todos brindan elementos para repasar las características del mismo. Por ejemplo, la cuestión de la proletarización de los ciudadanos en manos del Estado para las producciones públicas de mercadería comercializable; los intentos de regular y controlar la dimensión familiar y filial de las mujeres y varones de la época; las relaciones dinámicas y escurridizas entre la Iglesia Católica (en Roma y en Paraguay) y la administración pública; los dilemas de la construcción racial y étnica del relato de la nación paraguaya; la propiedad de la tierra y su disputa como elemento central de estatidad y defensa a la propiedad pública o privada; la evolución de la justicia y de los juzgados; el desarrollo de una política monetaria, entre otros elementos.

Queremos agregar en este apartado la definición de Pastore (1993) sobre el Estado Lopista, dado que este autor arriesga un concepto, asegurando que los López proponían un estado mercantilista y que su interés en aumentar el patrimonio del Estado respondía a su deseo de que la clase dominante pudiese acceder a tierras y producciones. Pastore sostiene: "Pensaban los gobernantes del Paraguay que el interés privado del Estado era el mismo que el de la nacionalidad y que el interés privado de los habitantes del país debía estar siempre supeditado al interés privado del Estado" (1993: 159).

Consideramos que este solapamiento absoluto de intereses privados de la elite con acciones públicas de Estado no obedece a patrones tan lineales y que, como hemos descripto, las estructuras sociales también moldean al grupo que ejerce el poder. 


\section{El Estado en Paraguay durante el gobierno de Carlos Antonio López. Una propuesta teórica-histórica}

\section{¿Fue el de Carlos Antonio López un Estado Nacional? El Paraguay del Siglo XIX desde la matriz analítica de Oszlak}

El 25 de noviembre de 1842, el Congreso ratificó la independencia y declaró que la República era una nación libre de hecho y de derecho, independiente de toda injerencia o poder ajeno; y que nunca sería patrimonio de una persona o un grupo familiar. Lo primero fue en respuesta (o casi una transcripción literal) a una solicitud expresa de López que, tras cerrar su Mensaje del 24 de noviembre de 1842 sostuvo:

"Treinta y un años llevamos de nuestra existencia política, desde que por nuestros esfuerzos nos separamos de la metrópoli española y de todo otro poder extranjero. Este sentimiento, uniforme en toda la República, jamás ha sido contradicho por acto alguno que pudiera desvirtuarlo. Nuestra independencia de hecho es la base fundamental de nuestras libertades, y a donde debe sostenerse para siempre el edificio político de nuestra asociación republicana. Es tiempo que entre los fastos de nuestra libertad se registre un monumento eterno en que declaréis explícitamente lo que tantas veces ha manifestado la voluntad general de la República, de quien hoy sois un órgano indefeciente. La república entera la aclama con entusiasmo, y es justo satisfacerla, declarando solemnemente la independencia de nuestra República del Paraguay, bajo las bases que sean de vuestra soberana aprobación (...)" (López, 1842).

Los gobiernos de ambos López (Carlos Antonio y su sucesor, Francisco Solano) han sido reconocidos por la literatura específica como un período de consolidación política en Paraguay, atribuyéndole al primero de ellos el logro de erigir una economía prolífera, la independencia económica, y un proyecto social nacionalista propio, además de haber conquistado avances técnicos y productivos (la primera imprenta, la fundición, el ferrocarril, el arsenal, el astillero, etc.). En complemento, también logró que los países vecinos acepten la independencia del Paraguay y consolidó un sistema de relaciones internacionales sobre la base de enviados y de intercambio diplomático con otros países.

Brezzo (2008) explica que una parte de la narrativa histórica que le atribuye al gobierno de López un continuo de logros y ningún fracaso, sostenidos en su visión de Estado, es una creación surgida de la necesidad de reconstruir el mito nacional y los héroes que hicieron posible ese momento mítico.

El período lopista generó un conjunto de controversias en las formas de análisis tanto de la época (pueden leerse diarios de viajeros, intervenciones de diplomáticos, reacciones de gobiernos vecinos, documentos y archivos que esbozan opiniones completamente disímiles sobre el Gobierno de Carlos Antonio y de su hijo Francisco Solano) como en los análisis posteriores de historiadores dedicados a este proceso. Por ejemplo, mientras que Areces (2010) explica que la política de la propiedad pública de la tierra y otras medidas tendientes a controlar la producción fueron interrumpidas por la Guerra, otros autores como Pastore (1993), Telesca (2009) y Schvartzman (1989) plantean que es un rasgo de superficialidad caracterizar al 


\section{Magdalena López}

gobierno de López como un régimen de control absoluto de las tierras puesto que la tendencia a la privatización ya existía y la explotación laboral era evidente en las producciones, lo que generó permanencia de regímenes de trabajo esclavo, semi esclavo y, progresivamente, asalariado, algo que también confirma Rivarola (2010). Oszlak remarca el carácter contradictorio y no lineal del proceso de formación del Estado, lo cual nos permite pensarlo como un proceso acumulativo pero también con contracorrientes. En la creación de este Estado nacional, debía coordinarse un conjunto de instituciones de poder, que organizasen a la sociedad, previniesen revueltas internas, ayudasen a controlar el descontento popular, organizasen una matriz económica y se sacasen progresivamente de encima a los resabios de un sistema colonial que aún perduraba, sobre todo en el caso paraguayo, del continuador de Francia.

Analizaremos a continuación, brevemente, cuatro requisitos de estatidad que describimos anteriormente.

\section{Externalizar el poder}

En su libro "La formación del Estado argentino", Oszlak plantea que el punto de partida de toda construcción de Estado nacional es la emancipación, es decir, la independencia. Pero, como bien expresa, esta ruptura no significó una supresión automática del orden colonial y de sus formas de inserción de las previas colonias dentro del comercio mundial. Muchos estados nacientes se sostuvieron casi íntegramente sobre la aceptación externa de su unidad soberana. El caso paraguayo es diferente, puesto que este reconocimiento llegó décadas después de la independencia.

En Paraguay, el poder político a) se erigió de manera centralizada (durante el gobierno de Gaspar Rodríguez de Francia y de los dos López), b) sufrió modificaciones en cuanto a su ejercicio con, al menos retóricamente, una mínima separación de poderes (con Carlos Antonio López), y c) logró el establecimiento de un orden interno relativamente estable, todo antes de que el nuevo Estado adquiriese el reconocimiento externo de países vecinos.

En todo caso, en el período de Gobierno de Carlos Antonio López Paraguay firmó 31 acuerdos, convenciones y tratados internacionales, de los cuales 5 corresponden al reconocimiento de la Independencia del Paraguay. ${ }^{8}$ Además, incluyen también una batería de Convenciones firmadas con Estados Unidos de América en $1859^{9}$ y una

\footnotetext{
8Bolivia en 17 de junio de 1843; Brasil en 14 de septiembre de 1844; Uruguay en 14 de junio de 1845, Venezuela en 11 de mayo de 1847, y Argentina en 17 de julio de 1852.

9 Tratado de Amistad, Comercio y Navegación con los Estados Unidos de América. Asunción, 4 de febrero de 1859. Promulgación: 11 de febrero de 1859. Canje: Washington, 7 de marzo de 1860. Convención especial relativa a las reclamaciones de la "Compañía de Navegación de los Estados Unidos de América y del Paraguay". Asunción, 4 de febrero de 1859.
} 


\title{
El Estado en Paraguay durante el gobierno de Carlos Antonio López. Una propuesta teórica-histórica
}

sentencia de acuerdo por un pleito que encontró su resolución mediante vías diplomáticas y no bélicas ${ }^{10}$.

La consolidación del poder se desarrolló lentamente hacia afuera, pero se iba construyendo hacia adentro. El monopolio estatal de la producción de madera y yerba mate (a partir de 1846), la organización urbana rural del territorio y la articulación incipiente de actividades, fueron medidas tendientes al desarrollo de un mercado interno, con vistas a la exportación que, según declaró Carlos Antonio López, estaba prácticamente anulada por los años de aislamiento durante el gobierno de su antecesor, que había anulado los vínculos comerciales con Corrientes y Brasil.

Nos interesa recapitular una experiencia muy particular, la del periódico El Paraguayo Independiente. Esta obra, publicada entre el 26 de abril de 1845 y el 18 de septiembre de 1852, contó con 118 ediciones y fue pensado como un periódico del Estado paraguayo, destinado a la lectura internacional de esa comunidad que, desde 1811, se había resistido a aceptar su estatus de unidad soberana. Surge más como un órgano político que como un periódico pues disputaría con la prensa argentina la independencia del país; $y$, una vez logrado el reconocimiento de la nación vecina, daría por cerrado su ciclo, sosteniendo:

\begin{abstract}
"Nuestro papel concluye en este número, y al cerrarlo tenemos la íntima complacencia de felicitar a nuestros compatriotas por la consecución de los tres grandes objetos de nuestras tareas: el reconocimiento de la Independencia de la República, el acuerdo definitivo de sus límites con la Confederación Argentina, y la libre navegación de nuestro pabellón por el río Paraná, y sus afluentes". ${ }^{11}$
\end{abstract}

Mediante este instrumento, Paraguay fue también parte de debates que se daban internacionalmente y se ponía sobre la mesa las opiniones y posturas del gobierno paraguayo. Era una forma de integrar un concierto del que Paraguay no era aún parte.

Luego de su cierre, el Estado comenzó a publicar otro emprendimiento editorial ya destinado a dar información y promover orden y normalización interna.

Todas estas medidas fueron posibles por el incentivo e inversión en la Imprenta Nacional.

\section{Institucionalizar la autoridad}

Este requisito de estatidad da cuenta de la posibilidad del Estado nacional de centralizar el poder de coerción, "monopolizar la violencia" en sentido weberiano.

\footnotetext{
${ }^{10}$ Sentencia de los Comisarios del Paraguay y de los Estados Unidos de América, en el asunto de las reclamaciones de la "Compañía de Navegación de los Estados Unidos del Paraguay". Washington, 13 de agosto de 1860.

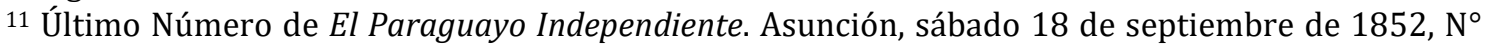
118.
} 
En la teoría de Oszlak el referente común y homogeneizador de la heterogénea presencia del Estado es la legítima invocación a su autoridad que presumiblemente encarna el interés general de la sociedad. Es decir, ante la caída del orden colonial y la irrupción de peleas internas por hacerse del poder, quien lograse hegemonizar sus intereses como los de la sociedad entera, sería quien, al mismo tiempo, lograse el monopolio de la fuerza física pero también conquistase un apoyo disgregado, de fuerzas sociales no necesariamente unidas.

"El grado de consenso o coerción implícito en estos actos de apropiación depende de la particular combinación de fuerzas sociales que los enmarcan. Pero en todo caso, siempre se hallan respaldados por alguna forma de legitimidad, derivada del papel que el Estado cumple como articulador de relaciones sociales, como garante de un orden social que su actividad tiende a reproducir" (Oszlak, 2011: 124).

El debate en torno a la conflictividad social en el Paraguay de la época sigue vigente. Las ideas de "pasividad" del sujeto social paraguayo por la falta de enfrentamientos explícitos -como los sucedidos en Argentina-sobrevolaron el pensamiento regional y local. Sin embargo, trabajos sobre los connatos y protestas, la organización de revueltas, la denuncia constante en organismos judiciales que detallaron estudios posteriores, dan cuenta de que esta supuesta pasividad fue más bien un subregistro histórico de las formas y trayectorias de resistencia social.

Acordamos con Oszlak y con Bohoslavsky y Godoy Orellana que, en los primeros años de la institución del Estado nacional, los organismos tendientes a la tarea coercitiva tuvieron una jerarquía y preponderancia mayor por sobre la construcción de la tarea de consenso. En este sentido, la exteriorización del Estado se vio acompañada por la institucionalización y búsqueda de legitimidad de milicias, instituciones jurídicas, vías estables de comunicación, áreas de confinamiento, normalización de penas por delitos, etc.

Revisando esta institucionalización, podemos encontrar que, durante el Consulado, se tomaron un conjunto de medidas tendientes a dotar de orden interno al Estado nacional. En 1842 se sancionaron el Estatuto provisorio de la Administración de la justicia y la Reglamentación de la Policía. En 1843 se institucionalizó el Departamento de Policía de la Capital. En 1845 se estipuló Servicio Militar por dos años para todos los varones mayores de 16 años.

En cuanto a la organización social, en 1842 se declaró la Ley de Libertad de Vientres y en 1848 se ejecutó la Supresión de pueblos de indios. Ambas medidas modificaron menos de lo esperado la constitución sociopolítica del Estado, pero le atribuyó un conjunto de derechos, sobre todo a los indígenas que serían, al menos declarativamente, considerados ciudadanos, lo que significaría, también, la obligatoriedad de ingresar al Servicio Militar.

Además de la obligatoriedad de las prestaciones militares, el Estado realizó, durante el régimen de López, una continuidad de levas por amenazas internas y externas. 


\section{El Estado en Paraguay durante el gobierno de Carlos Antonio López. Una propuesta teórica-histórica}

Claudio Fuentes Armadans destaca las de 1842, 1845, 1847, 1849, 1854, 1855, 1856 y 1857 (Fuentes Armadans, 2015). En tiempos de paz, los soldados serían utilizados para otras actividades y proyectos productivos del Estado. Si bien las conscripciones militares se extienden desde la colonia y fueron también utilizadas por Gaspar Rodríguez de Francia, durante el gobierno de Carlos Antonio López fueron normalizadas e institucionalizadas.

Un actor internacional que fue normalizado durante el período lopista, es la Iglesia Católica. Esta institución, que había sido fuertemente desarticulada por Gaspar Rodríguez de Francia, quedando prácticamente descabezada en el territorio, adquirió nuevamente estatus de religión de Estado, pero bajo supervisión del mismo.

Algunos elementos que queremos remarcar y que responden tanto al requisito de institucionalizar el poder como a diferenciarlo: a lo largo de estos años, el gobierno de Carlos Antonio López desarrolló una progresiva patrimonialización del Estado, es decir, fue adquiriendo edificios y terrenos para actividades administrativas, económicas y burocráticas, que cubriesen un amplio espectro de tareas públicas. Esto incluyó edificios en la ciudad de Asunción, pero también el terreno y edificio de la fundición de Ibicuy que fue una transformación de un espacio carcelario en 1850, los yerbales y bosques estatizados en 1846 y la toma directa de la explotación de los mismos.

En este sentido, se puede ver una articulación de intereses rurales-urbanos, que es el centro de la estrategia de surgimiento y consolidación de los Estados Nacionales. Enfocando en las variables económicas, autores como Cardozo y Faletto (1969) y Furtado (1969) remarcan el rol de la elite terrateniente y su unificación bajo una facción de la misma (y un líder) para instaurar el Estado, y la acción de la burguesía urbana que trataría de dinamizar el comercio exterior. Si bien esto no aplica linealmente para el caso paraguayo, puesto que el aislamiento político y la abrupta caída comercial de Paraguay en el Gobierno de Rodríguez de Francia, y la posterior incorporación al mercado regional que se da durante el de López, no marcaron un gran impacto en las cuentas nacionales, y fueron en gran medida bajo control estatal. Tampoco se produjo en Paraguay, como sí en el resto de los Estados vecinos, un endeudamiento con potencias extranjeras (como Gran Bretaña) y la exportación de productos a estas áreas no era tan relevante. Es decir, efectivamente la independencia paraguaya y el proceso de surgimiento del Estado fueron encabezados por miembros de una elite que era letrada, formada, con estudios, hispanoparlante, y con un pasar económico muy superior a la mayoría de la población; sin embargo, que hayan logrado imponer sin mediaciones un modelo capitalista de incorporación al mercado mundial no es evidente ni lineal; de hecho, hicieron falta muchos estudios pormenorizados de la propiedad de la tierra y la privatización, para dar cuenta de los procesos de conformación de una elite económica que se había desarmado durante el francismo.

Además de esta patrimonialización, de los intentos de abrir un mercado con el Estado como actor interviniente y de modificar algunas bases de organización social, 


\section{Magdalena López}

Carlos Antonio López encabezó otro hecho que sirve para comprender tanto la institución de una administración como la diferenciación del control: la incorporación del papel moneda nacional.

Hay muchos estudios que señalan que la incorporación de una moneda es una señal de estabilidad del Estado, pues espera que los ciudadanos confíen en la permanencia y durabilidad de ese patrón de intercambio; pero también una forma de dinamizar las relaciones económicas y de empezar a cobrar impuestos, es decir, extraer recursos de la sociedad para reproducción del sistema de gobierno, del aparato burocrático y de las relaciones socio económicas de producción.

\section{Diferenciar el control}

Durante el gobierno del primer López, elegido por Asamblea del Congreso, se redactó y entró en vigencia la Ley que establece la Administración Política del Paraguay (1844), considerada como la primera Constitución del Estado Paraguayo. Esta carta magna reorganizó el sistema político sobre la base de una nueva elite electoral y sin garantizar el derecho al sufragio universal. Las libertades individuales no fueron garantizadas y la causa que justificaba esta decisión, igualmente expresada en diversos documentos y discursos dados por el Presidente, era que el pueblo paraguayo "no estaba preparado para las artes de la libertad y la democracia por su profunda ignorancia", derivada de tantos años de oscuridad dictatorial. Esta "pesada herencia" francista, fue una de las razones por las que Carlos Antonio López insistió en desarrollar estrategias de educación inicial, aumentar el número de escuelas, enviar jóvenes a especializarse en diversas materias al exterior y promulgar un Catecismo propio.

La Constitución de 1844 establecía que el Congreso se reuniría cada cinco años y era el órgano que controlaba y revisaba las acciones desarrolladas por el Presidente. Esto se daba más en la norma escrita que en la práctica, dado que el Congreso más bien refrendaba al Ejecutivo. Además, es importante mencionar que el Legislativo varió de tamaño, acotándose a medida que pasaba el tiempo de 400 congresales en 1842 a sólo 100 en 1856, además, al tiempo que caía el número, subían los requisitos, dado que, de la posibilidad de voto general para elegir a propietarios representantes en 1842, se pasó a voto de propietarios para elegir a propietarios en 1856.

Esto hizo que Margarita Durán Estragó (2005:14) considerase que "la presidencia de CAL (1844-1862) continuó con la misma política autocrática de Francia, restringiendo poco a poco la participación en los congresos, reabiertos a partir de 1841".

El conjunto de medidas establecidas en la Ley y en otros documentos anexos (como la adopción en 1846 del Código de Comercio español), dividía los poderes y los estructuraba, organizaba el sistema electivo, planificaba actividades y garantizaba cierto encuadre a las actividades sociales y al comercio. Esta normativa, sumada a las destinadas a establecer sanciones a los actos delictivos y criminales, la institucionalización de un sistema de justicia y la creación de organismos con relativa independencia del poder centralizado, daban cuenta de un sistema de 


\section{El Estado en Paraguay durante el gobierno de Carlos Antonio López. Una propuesta teórica-histórica}

diferenciación del poder. Sin embargo, es importante remarcar que, en instancias de suma importancia, seguiría siendo el Presidente el último eslabón de la cadena de interpretación de la ley, atribuyéndose, por ejemplo, la decisión final en un proceso judicial, la condonación de una deuda o la suspensión de la pena capital. Por esta causa, muchos actores sociales apelaban hasta la última instancia, con la esperanza de, al llegar a oídos de Francia o de López, fuesen perdonados. ${ }^{12}$

En cuanto al régimen laboral, la esclavitud no fue abolida y los indígenas liberados constituyeron mano de obra disponible desposeída de sus tierras. El trabajo fue una forma de extracción de recursos, dado que el Estado detentaba la propiedad de la casi totalidad de la tierra de cultivos, de praderas y bosques (explotándolos de forma directa a partir de "habilitamientos" a particulares) y tuvo un papel central, a veces incluso de monopolio de producción y comercialización de bienes.

El sector privado explotó este sistema en forma directa o funcionando como agente intermediario con el Estado. Esto generó una naciente burguesía rural y comercial cercana al círculo presidencial.

Rivarola (2010) demuestra que, en el tiempo de López, la regimentarización militar del trabajo, los auxilios y el trabajo forzado de convictos se refuerzan e institucionalizan. La autora explica que, con López, creció el Estado y se subdividió la sociedad civil, haciendo que el primero deba crecer más, para satisfacer nuevas demandas. El Estado fue muy eficaz en transformar una sociedad con otros parámetros de trabajo (lo que Rivarola denomina población prelaboral) en mano de obra activa, aunque no pudo atravesar todos los fenómenos necesarios para convertir al campesinado en trabajador asalariado, pues no privatizó las tierras, no existió una migración masiva rural-urbana (que se dio progresivamente casi un siglo después), no se instalaron grandes industrias manufactureras, el sistema productivo continuó siendo precario, etc.

Seguimos a Ernesto Bohoslavsky y Milton Godoy Orellana afirmando que,

"la igualdad consagrada en los textos constitucionales a las personas (al menos a los varones), convivía con una realidad en la que la jerarquización étnica, de género y de clases era la regla: en la manera en que se resolvió ese dilema entre la promesa nacional-democrática universalista y una práctica excluyente es que algunos autores han encontrado el motor del Siglo XIX latinoamericano" (Bohoslavsky y Godoy Orellana, 2010: 19-20).

La recaudación de impuestos también sufrió modificaciones y fue variando en el tiempo, uno de los decretos iniciales es el de 19 de julio de 1843 en el que se sancionaba la falta de pago de impuestos y la falta de titularidad de propiedades y tierras. Esto sirvió para que el Estado se haga de las mismas, cuando no se podía mostrar la legítima posesión de éstas.

${ }^{12}$ Abundantes ejemplos de situaciones como estas son presentados en Potthas (1996). 
Tras la suspensión de los pueblos de origen indio, el poder central sustituyó a los cabildos, alcaldes y regidores con jueces de paz y jefes de milicias. La población debería pagar arriendo por las tierras que antes poseía. Esto fue, para Pastore, "el acto primigenio de fundación del Estado de Carlos Antonio López. El autor agrega que,

\begin{abstract}
"Ias tierras que habían sido defendidas por la Corona española como el último refugio de los nativos del Paraguay y de sus descendientes, pasaron al patrimonio privado del Estado, tomando nuevas formas los intereses económicos representados por éstos, incrustados en el Estado mercantilista y paternal, para librar otra batalla por la posesión de las tierras y las riquezas que contienen, y por el sometimiento político y económico del pueblo" (Pastore, 1993: 129).
\end{abstract}

La ley de 1844 fue complementada por la Reforma constitucional de 1856 que alteró el sistema y formato de selección, disminuyendo la edad del potencial presidente y permitiendo que un militar llegue al cargo, todo indicaría que el viejo López quería dejar a su hijo Francisco Solano López a cargo del Estado nacional naciente.

Confirmamos junto a Oszlak que Paraguay, como otros "Estados latinoamericanos, en su etapa formativa, fueron desarrollando sucesivamente sus aparatos de represión, de regulación y de acumulación de capital social básico. Sus cristalizaciones institucionales -en forma de legislación, organismos públicos, mecanismos administrativos y pautas de asignación de recursos- reflejaron las diversas combinaciones a través de las cuales el Estado procuró resolver los problemas del "orden" y el "progreso". Pero todo esto exigía recursos. Es decir, el Estado debía desarrollar paralelamente una capacidad extractiva y un aparato de recaudación y administración financiera que aseguraran su propia reproducción, de modo de consolidar su poder, legitimarse y continuar sosteniendo las condiciones de expansión económica" (Oszlak, 2014: 132).

\title{
4. Internalizar una identidad colectiva.
}

Habíamos adelantado que este requisito de estatidad es, quizás, el más difícil de rastrear, en primera instancia, porque la conformación de una idea de nación en América Latina es muy desigual a la europea.

Las diferentes escuelas de la teoría del Estado suelen asociar el surgimiento o la consolidación de esta forma de organización política-social a dos elementos más: el protagonismo del capitalismo como articulador de las relaciones económicas y la preeminencia de la nación como amalgama invisible de identidad e imaginarios compartidos.

Los autores latinoamericanos encontraron un rasgo del imaginario nacional en las guerras de la independencia o en las conformaciones sociales surgidas en torno a la dominación colonial, pensando así la identidad como una resistencia sociocultural étnica. 


\section{El Estado en Paraguay durante el gobierno de Carlos Antonio López. Una propuesta teórica-histórica}

En Paraguay, las guerras de la independencia no tuvieron un especial impacto como tuvieron en otros Estados regionales. Sin embargo, el debate sobre la nación tomó otros caminos, que incluyeron la especificidad nacional (nación campesina, nación guaraní, etc.).

En sus Mensajes, Carlos Antonio López habló a un "pueblo" que, si bien puede entenderse como un recurso retórico, también da cuenta de una unidad reconocible a partir de no ser otro también identificable.

En su trabajo sobre las consecuencias sociodemográficas y territoriales, Ignacio Telesca (2009) explica que la constitución social del Paraguay no respondía a un conjunto unificado de actores que compartiesen lo que podríamos llamar un horizonte de solidaridades y representaciones conjuntas. Eran más bien grupos con uniones locales y organización más localista.

Si bien adherimos en parte a esta descripción, consideramos que la sociedad que se construye en paralelo a la consolidación estatal tiene también una "otredad incorporada", es decir, responde también lentamente a la conformación de un imaginario de pertenencia, a medida que incorpora por una parte el conocimiento de no ser parte de los vecinos (plasmada en el temor a una invasión o anexamiento muy fuertes hasta mediados de 1850), y por otra, la pertenencia económica a un enclave de capitalismo que crece.

Acordamos con Oszlak en que,

"la identificación con la lucha emancipadora, precario componente idealista de la nacionalidad, fue insuficiente para producir condiciones estables de integración nacional. La base material de la nación recién comenzó a conformarse con el surgimiento de oportunidades para la incorporación de las economías locales al sistema capitalista mundial y el consecuente desarrollo de intereses diferenciados $e$ interdependientes generados por tales oportunidades" (Oszlak, 2011:137)

La condensación de este sentimiento, puede verse un poco más articulada hacia los albores de la Guerra contra la Triple Alianza, aunque, siguieron existiendo grupos que no se identificaban con este ideal de unión y que participaron en los ejércitos por coacción estatal, a cambio de su libertad o por reclutamientos forzados.

Desde el exterior, tanto en Argentina como en Uruguay y Brasil, Paraguay era construido con un relato de un "otro muy diferente". La sociedad era construida como bárbara, primitiva y pobre, con poco desarrollo intelectual y económico. Esta capacidad extractiva se adaptó a la capacidad de cada país y la disponibilidad.

Esta construcción de nación, que en palabras de Oszlak presupone un desarrollo del plano material de relaciones sociales capitalistas, también implica un plano ideal de creación de símbolos y valores que promuevan sentimientos de pertenencia, es decir, moneda (1845), sistemas de intercambio establecidos, rutas, arquitectura comercial, pero también himnos (escrito para Carlos Antonio López en 1846), bandera (adoptada en 1842), "la creación de símbolos y valores generadores de 


\section{Magdalena López}

sentimientos de pertenencia que -para usar la feliz imagen de O'Donnell- tienden un arco de solidaridades por encima de los variados y antagónicos intereses de la sociedad civil enmarcada por la nación" (Oszlak, 2011: 118).

Un esfuerzo estructurado por fortalecer este sentimiento lo constituyeron los catecismos políticos, pensados para distribuirse en escuelas y ser impartidos por educadores y religiosos. Sin embargo, es imposible medir cuánto de esta prédica estatista nacionalista llegó a la sociedad paraguaya que era en gran medida analfabeta y dependía de los intermediadores del saber.

\section{Conclusiones}

Este trabajo intentó complementar un campo de estudio que no ha sido profundizado en Paraguay, pues quedó en el hiato de al menos dos disciplinas.

Hemos analizado el período de gobierno de Carlos Antonio López (tanto de cónsul como de presidente) a partir de una de las propuestas teórico-metodológicas para analizar el surgimiento y consolidación del Estado Nacional en Latinoamérica. Arribamos así a la conclusión de que el Estado lopista logró condensar al menos cuatro requisitos centrales de estatidad.

El Estado nacional paraguayo se construyó sobre la base de la coerción y el consenso, siendo lo primero mucho más importante al inicio del proceso y lo segundo se fue cercenando progresivamente, con la disminución del número de Congresales y el agudizamiento de los requisitos para ser elector.

Si bien el eje centralismo-federalismo no fue central en Paraguay, la disputa en torno a la producción agraria y la relación del polo urbano con el rural sí lo fue. Frente a esto, una medida original de López fue la de estatizar los bosques y yerbales y que fuese el Estado el encargado mayoritario de la explotación y la comercialización (e, incluso, de subarrendar).

Las disputas intra-elite se dieron fuertemente durante el Gobierno de Francia, quien desnutrió los espacios de socialización de la elite, forzándola a recluirse al ámbito privado. Una vez llegado al gobierno, López intentó rearticular estos espacios y, junto con el desarrollo de un modelo económico, gestó un fortalecimiento de un grupo privilegiado.

Existieron resistencias generales o particulares, pequeñas resistencias, modos de enfrentamiento al régimen de sectores subordinados que fueron analizados por trabajos diversos y que mostraron que la construcción del Estado fue un proceso complejo, con tensiones.

Al tiempo que López avanzó con una férrea campaña para lograr la aceptación de Paraguay como unidad soberana por parte de los Estados vecinos, desarrolló un conjunto de medidas tendientes a extender la presencia del Estado en el territorio nacional y, con ello, también la presencia del mercado con avances técnicos, tecnológicos y monetarios. En paralelo, reforzó la construcción de un "nosotros" que intentaba que impregnase en la población, con un disímil nivel de interpelación.

Esto no quiere decir, como han escrito muchos autores, que el período de López fue de un desarrollo sociopolítico y de un despegue económico únicos en la región, sino 


\section{El Estado en Paraguay durante el gobierno de Carlos Antonio López. Una propuesta teórica-histórica}

que existió, a pesar de las acusaciones de "barbarie" a la que fue expuesto Paraguay, un Estado nacional que, con las mismas contradicciones que los proyecto vecinos, se erigía en el contexto sudamericano.

Los modelos existentes con prestigio y legitimidad de lo "posible", las formas de pensar esta nueva organización político-administrativa y las herramientas disponibles para hacerlo no surgieron de Carlos Antonio López, como un visionario de la Patria, sino que eran un conjunto de ideas que circulaban en el contexto de las elites de la época y respondían a un grupo de conceptos. Paraguay no quedó fuera de ese circuito.

Las originalidades del Estado nacional lopista tienen que ver con lo tardío de su aceptación por parte de otros Estados, la forma productiva estatal-centrada de algunas de sus ramas económicas y la pronta incorporación de elementos de división de poderes y sistemas de control al sistema de gobierno (aunque sólo de forma discursiva-normativa pues, en muchos casos, el Presidente seguía siendo la autoridad única)

El Paraguay de la temprana independencia tenía una dependencia comercial de territorios vecinos que, durante el relativo aislamiento del gobierno de Francia, se interrumpió, siendo una tarea de López la reconstrucción de estos lados internacionales, que le significaría tener un ingreso al sistema capitalista global.

Esta incorporación se logró mediante la proletarización de actores sociales, que fue conflictiva y con procesos de mayor y menor alcance. La coexistencia de producción y comercio privado (tierra, bienes, esclavos) y pública (tierra, bienes, trabajadores forzados) también solapó estructuras diferentes de orden y planificación estatal.

Existieron intentos frustrados de organizar las relaciones maritales y conyugales para lograr una mayor incorporación al sacramento católico, para dotar a la población de un sistema de organización familiar-religiosa. Esto fue parte de una política de conjugar Estado con religión, algo que no sólo hace al orden político, sino al establecimiento de un rasgo identitario compartido más.

Todas estas medidas dan cuenta de una relación pujante con sectores marginales y relegados, una característica que también atañe a las demás sociedades de la época. La incorporación del dinero y la concentración, coordinación y estructuración tributaria (de la mano del Ministerio de Hacienda y otras instituciones similares) marcan también un intento de normalizar los intercambios precapitalistas de una forma financiera más modernizada, recaudar recursos de la sociedad por parte del Estado y darle credibilidad al Estado como ente capaz de legitimar y perdurar el acuerdo simbólico del dinero.

Indistinto del grado de acuerdo o desacuerdo con las medidas antidemocráticas de López o con la centralización del poder, existen en su período de gobierno rasgos de un Estado nacional, aunque luego de la Guerra contra la Triple Alianza, se haya empezado de nuevo, considerando que lo previo era primitivo o inexistente.

\section{Bibliografía citada}


Abente Brun, D. (1989). “Foreign Capital, Economic Elites and the State in Paraguay during the Liberal Republic (1870-1936)". Journal of Latin American Studies. Vol 21, № 1-2. Junio, pp- 61-88.

Areces, N. y González de Bosio B. (2017). El Paraguay durante los gobiernos de Francia y de los López. Asunción: El Lector.

Areces, N.(2010) "De la independencia a la Guerra contra la Triple Alianza (18111870)”. En Telesca, I. (coordinador). Historia del Paraguay. Asunción: Taurus.

Bohoslavsky, E. y Godoy Orellana, M. (2010). "Introducción. Ideas para la historiografía de la política y el Estado en Argentina y Chile, 1840-1930". En Ernesto Bohoslavsky y Milton Godoy Orellana (editores), Construcción estatal, orden oligárquico y respuestas sociales. Argentina y Chile, 1840-1930. Buenos Aires: Prometeo.

Brezzo, L. (2008). “En el mundo de Ariadna y Penélope: hilos, tejidos y urdimbre del nacimiento de la historia en Paraguay" en Polémica sobre la Historia del Paraguay. Asunción: Tiempo de Historia

Brezzo, L. (2011). Reconstrucción, poder político y revoluciones (1870-1920). En I. Telesca (Coord.), Historia del Paraguay (pp. 199-224). Asunción: Taurus.

Caballero Campos, H. (2009). Antología del Pensamiento Político y Social Paraguayo. Volumen I, Asunción: FONDEC.

Caballero Campos, H. (2013). El País ocupado. Asunción: El Lector.

Caballero Campos, H. (2015). “Entre el recuerdo y la reivindicación: apoteosis, el álbum conmemorativo de la inauguración del Panteón Nacional de los Héroes". Revista Folia Histórica del Nordeste, № 24, pp. 115-130.

Campos, L. (2010). Apuntes de historia económica del Paraguay. Desarrollo, auge y decadencia de una economía de enclaves. Asunción: Intercontinental.

Capdevila, L. (2010). Una guerra total: Paraguay, 1864-1870. Ensayo de historia del tiempo presente. Buenos Aires: SB editorial y CEADUC.

Castells, C. (2011) "En torno a 'Formación histórica de la Nación Paraguaya'”, ponencia presentada en el IV Taller Paraguay desde las Ciencias Sociales. Rosario. 


\section{El Estado en Paraguay durante el gobierno de Carlos Antonio López. Una propuesta teórica-histórica}

Centeno, M. (2002). Blood and Debt. War and the Nation-State in Latin America. Pensilvania: Pennsylvania State University Press.

Chartrain, F. (2013). La iglesia y los partidos en la vida política del Paraguay desde la Independencia. Asunción: CEADUC.

Chávez, J. (1955). El Presidente López. Vida y Gobierno de Don Carlos. Buenos Aires, Ayacucho.

Cooney, J. y Whigham T. (comp.). (1994). El Paraguay bajo los López. Algunos ensayos de historia social y política. Asunción: CPES.

Couchonnal Cancio, A. (2017). Donde nací como tú. Perspectivas en torno a la articulación de un sujeto político en Paraguay. Asunción: Tiempo de Historia,.

Creydt, 0. (2007). Formación Histórica de la Nación Paraguaya. Pensamiento y vida del Autor. Asunción: Servilibro.

Durán Estragó, M. (2005). Catecismo de San Alberto. Adaptado para las Escuelas del Paraguay. Gobierno de Francisco Solano López. Asunción: Intercontinental.

Fernando, C. y Faletto, E. (1969). Dependencia y Desarrollo en América Latina, México: Siglo XXI.

Fuentes Armadans, C. (2018). La maldición del legionario. Cómo se construyó un estigma político autoritario en el Paraguay. Asunción: Tiempo de Historia y Sociodata.

Fuentes Armadans, C. (2015)."El reclutamiento militar en la posguerra (18691904)”. En López, M. y Taboada, V. (coordinadoras) Violencias. Reflexiones sobre sus diversas formas en Paraguay. Asunción: Arandura.

Furtado, C. (1969). La economía Latinoamericana desde la Conquista Ibérica hasta la Revolución Cubana. Santiago: Editorial Universitaria.

Galeano, L. (2009). La hegemonía de un Estado débil. Asunción, CPES.

González Bozzolasco, I. (2017). “Fernando López-Alves y su caracterización del caso paraguayo. Un análisis de su trabajo 'La formación del Estado y la democracia en América Latina 1830-1910'”. E-l@tina Revista electrónica de estudios latinoamericanos. Universidad de Buenos Aires, Vol. 15, № 59, pp. 75-82.

González, N. (1935). El Paraguay Eterno. Asunción: Guarania.

González, N. (1942). "Presentación a la Obra de Carlos Antonio López", en La Emancipación Paraguaya. Asunción:mGuarania. 


\section{Magdalena López}

González, N. (1983). El Milagro Americano. Asunción: Cuadernos republicanos. Guerra Vilaboy, S. (1984). Paraguay: de la independencia a la dominación imperialista 1811-1870. La Habana: Editorial de Ciencias Sociales.

Heyn Schupp, C. (1982). Iglesia y Estado en el Paraguay durante el gobierno de Carlos Antonio López (1841-1862). Estudio jurídico-canónico. Asunción: Biblioteca de Estudios Paraguayos.

Kleinpenning, J. (2009). Rural Paraguay 1870-1963. A geography of progress, plunder and poverty. Madrid, Iberoamericana-Vervuert.

Lempériére, A. (2007). "La historiografía del Estado en Hispanoamérica. Algunas reflexiones". En Guillermo Palacios (editor). Ensayos sobre la nueva historia política de América Latina. Siglo XIX. México: Colegio de México.

López-Alves, F. (2003). La formación del Estado y la democracia en América Latina 1830-1910. Bogotá: Norma.

Maestri, M. (2016). Paraguay: la república campesina, 1810-1865. Asunción: Intercontinental.

Mariñas Otero, L. (1978). Las constituciones del Paraguay. Madrid: Centro Iberoamericano de Cooperación.

Nettl, J. (1968). “The State as a Conceptual Variable”. World Politics, Vol. 20, № 04, pp. 559-592.

O’Donnell, G. (1978). "Apuntes para una teoría del Estado". Revista Mexicana de Sociología, Vol. 40, № 4, pp. 1157-1199.

Oszlak, O. (2011). "Formación histórica del Estado en América Latina: elementos teórico-metodológicos para su estudio", en AA.VV. Lecturas sobre el Estado y las políticas públicas: Retomando el debate de ayer para fortalecer el actual. Buenos Aires, Jefatura de Gabinete de Ministros.

Oszlak, 0. (2014). La formación del Estado argentino. Orden, progreso y organización nacional. Buenos Aires: Ariel.

Pastor Benítez, J. (1990). Carlos Antonio López: estructuración del Estado paraguayo. Asunción,

Pastore, C. (1972). La lucha por la tierra en el Paraguay. Montevideo: Editorial Antequera.

Pastore, M. (1993). State-led "industrialization"; the evidence on Paraguay, 18521870. New Orleans, Center for Latin American Studies, Tulane University, New 


\section{El Estado en Paraguay durante el gobierno de Carlos Antonio López. Una propuesta teórica-histórica}

Orleans, LA, Latin American Studies Program, Cornell University. Disponible en https://mpra.ub.uni-muenchen.de/27505/ MPRA Paper No. 27505.

Pérez Acosta, J. (1948). Carlos Antonio López: Obrero máximo. Buenos Aires, Guarania.

Potthast, B. (1996). ¿ "Paraíso de Mahoma" o "País de las Mujeres"? El rol de la familia en la sociedad paraguaya del siglo XIX. Asunción: ICPA.

Rivarola, M. (2010). Vagos, pobres y soldados. La domesticación estatal del trabajo en el Paraguay del Siglo XIX. Asunción: Servilibro.

Rosanvallon, P. (1990). L'Etat en France. Paris, Du Seuil.

Schvartzman, M. (1989). Contribuciones al estudio de la sociedad paraguaya. Asunción: CIDSEP.

Skocpol, T. (1995). “El Estado regresa al primer plano: estrategias de análisis en la investigación actual”, en Romeo Grompone (editor); Alberto Adrianzén; Julio Cotler y Sinero López (compiladores). Instituciones políticas y sociedades. Lecturas Introductorias. Lima, IEP.

Susnik, B. (1992). Una visión socioantropológica del Paraguay del siglo XIX. Asunción: Museo Etnográfico Andrés Barbero.

Telesca, I. (2009). Tras los expulsos. Cambios demográficos y territoriales en el Paraguay después de la expulsión de los jesuitas. Asunción, CEADUC.

Telesca, I. (2010). "Paraguay en el Centenario: la creación de la nación mestiza”. Historia Mexicana, v. 60, nำ1, pp. 137-195.

Telesca, I. (2017). "La población afrodescendiente en la conformación agraria del Paraguay hasta la guerra contra la Triple Alianza". Territórios ao Sul: escravidão, escritas e fronteiras coloniais e pós-colonias na América. Río de Janeiro, 7Letras, pp. 44-60.

Viola, A. (2004). Cárceles y otras penas. Época de Carlos Antonio López. Asunción: Servilibro.

White, R. (1989). La primera revolución popular en América Latina (1810-1840). Asunción: Carlos Schauman Editor.

Recibido: 04/01/2019

Evaluado:20/02/2019

Versión Final: 10/04/2019 